\title{
TAXA DE CÂMBIO E RENDA EXTERNA COMO DETERMINANTES DA BALANÇA COMERCIAL DE PRODUTOS BÁSICOS NO ESTADO DO PARANÁ, 2000 A 2015
}

\section{Resumo}

\author{
Pietro André Telatin Paschoalino* \\ Carlos Eduardo Caldarelli* \\ J osé Luiz Parré*
}

As discussões acerca do processo de desindustrialização no Brasil têm se tornado recorrente e os resultados ensejam muita controvérsia. Um fator que contribui para isso é a heterogeneidade dos dados para o Brasil e dados muito agregados de comércio externo. Neste sentido, os estudos com escopo regional parecem uma estratégia para tal análise. Assim, este estudo tem por objetivo aclarar a relação entre câmbio e renda externa sobre a Balança Comercial - BC - de bens básicos no Paraná, para o período de2000 a 2015. Foram utilizadas ferramentas de séries temporais - modelo VECM e elasticidades de transmissão de curto elongo prazo - para tal. Os resultados sinalizam que a BC dos produtos básicos no estado é elástica tanto em relação ao câmbio quanto à renda externa - responde mais que proporcionalmente - o que destaca que crescimento da renda externa acelerado e desvalorizações cambiais levam a uma intensificação nas exportações de produtos básicos.

Palavras-chave: Câmbio; Comércio exterior; Modelo VECM; Bens básicos.

\begin{abstract}
Discussions about the process of deindustrialization in Brazil have become recurrent and the results provoke much controversy. One contributing factor is the heterogeneity of the data for Brazil and very aggregate external trade data. In this sense, studies with regional scope seem a strategy for such analysis. Thus, this study aims to clarify the relationship between foreign exchange and external income on the Trade Balance - TB - of basic products in Paraná, for the period from 2000 to 2015. Time series tools were used - VECM and short and long-term transmission elasticities - for such. The results indicate that the TB of basic products in the state is elastic both in relation to foreign exchange and external income - Responds more than proportionately - which highlights that growth accelerated of foreign incomeand currency devaluations lead to an intensification of basic products exports.
\end{abstract}

Keywords: Exchange; Foreign trade; VEC model; Basic Goods.

JEL code: F10; F40; C32

* Universidade Estadual de Maringá (UEM). 


\section{INTRODUÇÃO}

À medida que estudos sobre a determinação da balança comercial foram sendo desenvolvidos, diversos questionamentos e discussões sobre o impacto da taxa de câmbio sobre a balança comercial começaram a surgir, para alguns autores essa taxa seria o principal determinante para o saldo da balança comercial, sendo ainda responsável pela suposta "doença holandesa"1 e desindustrialização no Brasil nas décadas de 1980 e 1990 (Bresser e Marconi 2008). Desta feita, é de relevante importância a análise da influência da taxa de câmbio sobre a Balança Comercial.

A taxa de câmbio e sua relevância sobre a atividade econômica tem recebido muita atenção na literatura econômica sobre o tema, sobretudo a questão industrial. Segundo Souza, Basílio e Oreiro (2014) uma taxa de câmbio acima do equilíbrio industrial leva a uma melhora de setores intensivos em capital.

Os dados do IPEADATA (2016) mostram que o índice médio da taxa de câmbio efetiva real para exportações de manufaturados ${ }^{2}$ apresentou valorização de aproximadamente 45,24\% entre 1990 e 1999, ano este em que o Banco Central instituiu o regime de câmbio flutuante. Além disso, os dados do IBGE (2016) demostram que o índice da produtividade da indústria de transformação ${ }^{3}$ no ano 1990 era menor que em 1984, apresentando, todavia, significativa melhora entre 1990-2000 com uma taxa de crescimento superior a 110\%, porém no período mais recente 2001-2012 sua taxa de crescimento fora muito mais tímida, cerca de $21 \%$.

Posto isso, outro fator relevante que merece atenção, quando da análise da Balança comercial, é a participação relativa da China no comércio exterior brasileiro e sua elevação nas últimas décadas. Em 2016 a China foi o maior parceiro comencial brasileiro, o país importou mais de 35 bilhões de dólares do Brasil e nos exportou cerca de 30,7 bilhões, sendo assim, neste ano o país foi responsável por aproximadamente $25 \%$ do saldo da balança comercial brasileira. Porém, para alguns autores como Acioly, Pinto e Cintra (2011) o acirramento das relações de comércio entre Brasil e China pode ser responsável por uma especialização regressiva da pauta exportadora brasileira. O que torna necessário, em uma análise da balança comercial, considerar além do câmbio, a questão da renda externa, para que possa ser possível captar a presença deste processo.

Desta maneira, de acordo com as exposições feitas, este estudo tem por intuito entender à importância relativa da taxa de câmbio e da renda externa como determinantes da balança comercial dos produtos básicos do estado do Paraná, um estado cuja geração de divisas conta com substancial participação desse setor. Segundo dados do MDIC (2016) o resultado registrado da balança comercial do Paraná no ano de 2015 fora de aproximadamente US\$ 2,285 bilhões, já o

1 O termo pode ser entendido como sendo um tipo de falha de mercado decorrente da abundância de recursos naturais utilizados na produção de commodities, essas seriam compatíveis com uma taxa de câmbio mais apreciada e suas exportações apreciariam ainda mais a taxa de câmbio inviabilizando a produção e exportação dos demais setores da economia (Bresser e Marconi 2008).

2 Média de $2010=100$.

3 Média de $1991=100$. 
resultado da balança comercial de produtos básicos do estado no mesmo período fora de US\$ 6,318 bilhões, ou 2,76 vezes a balança geral. O objetivo principal é determinar através de um modelo vetorial de correção de erros, como se configura a elasticidade da balança comercial em relação à renda e ao câmbio, tomados neste estudo com seus principais determinantes.

O trabalho está dividido em 5 seções, além desta introdução, a segunda seção traz o referencial teórico acerca da influência da taxa de câmbio e do produto externo sobre a balança comercial, assim como trabalhos empíricos acerca da balança comercial paranaense. A terceira seção discorre sobre a metodologia, na quarta seção é possível analisar os resultados e verificar a influência da taxa de câmbio e da renda externa sobre a balança comercial paranaense. Por fim, na última seção são tecidas as considerações finais.

\section{REFERENCIAL TEÓRICO}

Os trabalhos pioneinos de Marshall (1923) e Lerner (1944) buscaram estabelecer uma relação de longo prazo entre o saldo da balança comercial e as variações cambiais. Aceitas algumas suposições teóricas, os autores apontam que uma depreciação cambial implica em saldos positivos para a balança comercial, fenômeno conhecido como Condição de Marshall-Lerner - CML - . A explicação deriva do fato de que a depreciação cambial torna o produto doméstico mais barato e o produto estrangeiro relativamente mais caro, isto é, a depreciação cambial incentiva as exportações e desestimula as importações do país.

Segundo a CML, que pode ser considerada uma derivação da teoria da elasticidade preço da demanda, para uma desvalorização cambial causar um efeito positivo na balança comercial é necessário que a elasticidade das exportações e importações, em valor absoluto em relação à taxa de câmbio, seja maior que um. Nesse caso, o efeito sobre a balança comercial dependerá de dois efeitos, a quantidade (diminuição de importações), e do efeito custo (aumento do custo dos bens importados). A condição pode ser expressa como (Moura 2005).

$\left|\eta^{*}+\eta\right|>1$

Em que $\eta *$ é a elasticidade das exportações em relação à taxa de câmbio e $\eta$ a elasticidade das importações em relação à taxa de câmbio.

De acordo com Teles (2005), com o desenvolvimento das teorias acerca dessa temática, constata-se empiricamente que uma desvalorização cambial causa, inicialmente, uma queda no saldo das transações correntes e a partir de certo tempo, passa-se para um crescimento no saldo mais que proporcional à sua queda. Segundo Krueger (1983) a explicação para esse fato advém de que no momento da mudança da taxa cambial os bens estarem sendo negociados em contratos, que não podem ser quebrados, assim o aumento da taxa de câmbio encarece as importações já negociadas. No médio e longo prazo, esses contratos tendem a encerrar-se, sendo possível uma adequação à nova taxa de câmbio 
praticada, tendendo assim a elevar o saldo das transações correntes. Posto isso, destaca-se que os movimentos na balança comercial decorrentes de variações cambiais podem ser diferentes de acordo com a agregação utilizada.

Posto isso, a literatura econômica recente tem pautado a sua discussão em investigar se determinados países satisfazem ou não a CML. Desta monta, segundo Ferreira (1993) pode-se expressar a balança comercial por meio de um modelo teórico pela seguinte função:

$S=f\left(Y, Y^{*}, R P\right)$

OndeY é um indicador do nível de atividade econômica do país doméstico, $Y^{*}$ um indicador de atividade econômica no exterior e RP é um indicador dos preços relativos, geralmente representado pela taxa de câmbio real. Diversos estudos que tentaram explicar a queda do valor adicionado da indústria na década de 90 atribuíram a variável taxa de câmbio real como principal determinante dos resultados do período, ou seja, do processo de desindustrialização e suposta "doença holandesa" na qual o país estava por enfrentar (Bresser e Marconi 2008; Oreiro e Feijó 2010).

Já nos estudos que visam entender a mudança estrutural ocorridas nas últimas duas décadas, com o robusto crescimento da economia chinesa, foi o indicador de renda externa $\mathrm{Y}^{*}$ que passou a chamar a atenção como determinante da Balança Comercial, com um suposto processo que estaria ocorrendo na economia brasileira, o chamado "Efeito China".

O debate acerca da desindustrialização da economia brasileira aflorou na década de 1990 e cujo debate permanece até os dias atuais. Tregenna (2009) define o conceito atual de desindustrialização como sendo a queda do emprego industrial e do valor adicionado em relação, respectivamente, ao emprego total e ao PIB; considerada desindustrialização negativa quando ocorre a níveis de renda per capita inferiores às dos países desenvolvidos (Oreiro e Feijó 2010).

Como possíveis causas para a ocorrência do fenômeno surgiu-se a possibilidade de o país enfrentar a chamada "doença holandesa". Segundo Bresser-Pereira (2010) o aumento da taxa de câmbio e uma balança comercial que se mantém em equilíbrio seria uma evidência desse fenômeno, que poderia causar desindustrialização; diversos outros estudos seguem argumentação parecida (Bresser e Marconi 2008; Souza, Basílio, Oreiro 2014).

Em contraposição a essa tese de "doença holandesa" e desindustrialização da economia brasileira, estão estudos como de Nassif (2008) e Bonelli e Pessoa (2010). O primeiro destaca que a desindustrialização teria ocorrido nos anos 80 e que a não recuperação da indústria, pós 99 , ocorreu devido à queda da produtividade e crescimento brasileiro. O segundo estudo reforça que a desindustrialização ocorreu na década de 80, porém afirma que as reformas dos anos 90 (abertura financeira e comercial, desregulamentações, privatizações) impactaram negativamente o setor industrial, sendo esses os principais responsáveis pelo mau desempenho e não a suposta "doença holandesa”. 
A partir da Figura 1 é possível observar a evolução da média anual da taxa de câmbio efetiva real das exportações de manufaturados no período entre 1980 e 2015, já a Figura 2 dispõe dos dados sobre produtividade do trabalho para doze países selecionados no ano 2013.

Por meio da Figura 1é possível observar que a taxa de câmbio entre 1980 e 1998 se manteve bem abaixo da taxa registrada em 1999, ano em que o Banco Central institui o regime de câmbio flutuante. Além disso, é possível notar uma tendência de queda da taxa de câmbio no período como um todo, ou seja, de apreciação do real frente às moedas de seus parceiros comerciais, fato que pode ser correlacionado à continuação da desindustrialização brasileira no período recente. Segundo os dados do IPEADATA (2016), no ano 2000 o valor adicionado da indústria era de 17,22\% do PIB e no ano 2013 esse valor passa para apenas $13,13 \%$.

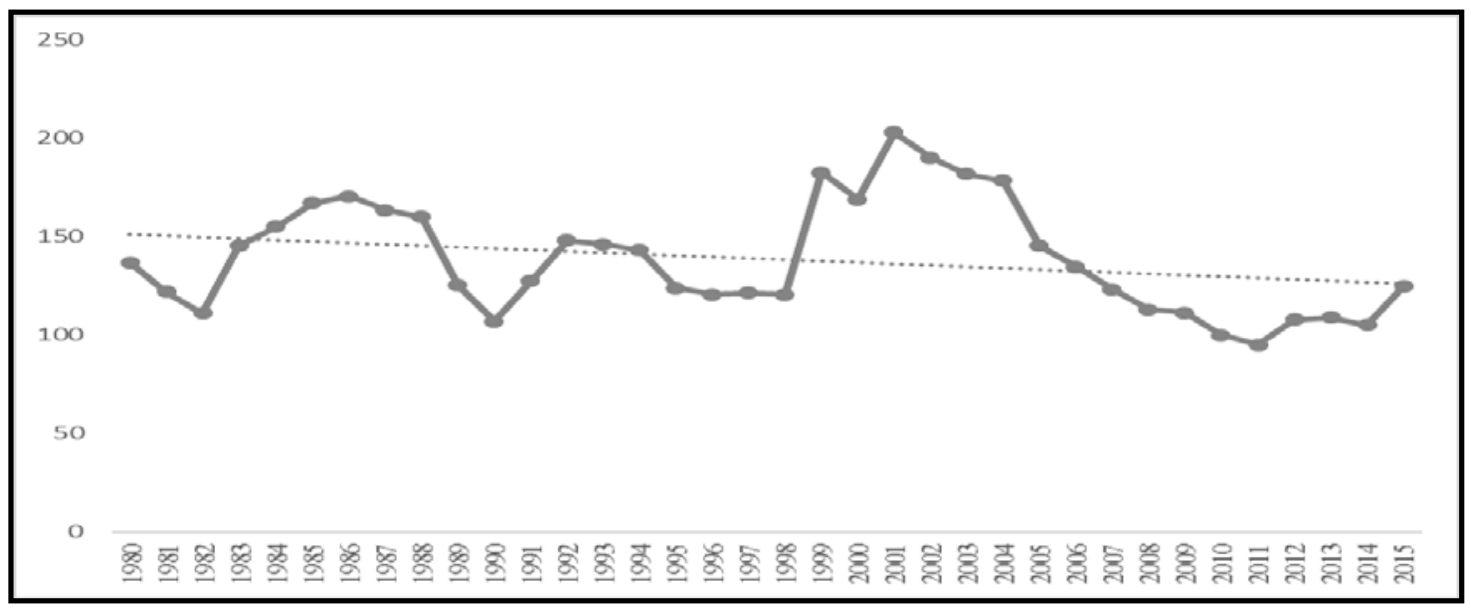

FIGURA 1. TAXA DE CÂMBIO EFETIVA REAL - INPC (exportações de manufaturados) 1980-2015.

Fonte: IPEADATA (2016).

Em relação à produtividade do trabalho (Figura 2) é possível verificar que no ano de 2013 o Brasil detinha menos de um quinto da produtividade dos EUA, além disso, entre os países desenvolvidos e em desenvolvimento selecionados, só apresentou uma produtividade maior que a China e a Índia. Ademais, estudo da CNI (2016) mostra que em relação à produtividade industrial o Brasil apresenta um crescimento muito lento, para a indústria de transformação a taxa de crescimento após o ano 2000 chegou a ser negativa. 


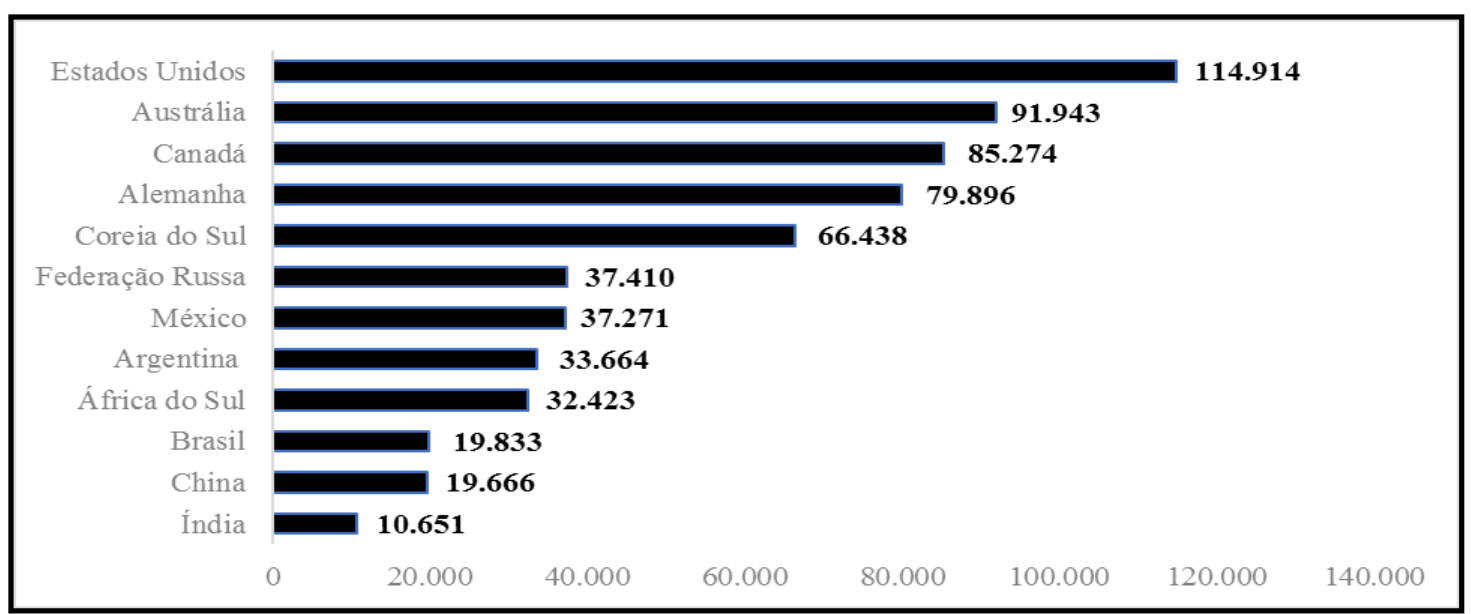

Figura 2. Produtividade do Trabalho para países selecionados, 2013 (US\$ PPP de 2013)

Fonte: The conference board total economy database.

Assim, tanto a apreciação cambial quanto a queda da produtividade, fatores apontados por autores como os determinantes da desindustrialização brasileira na década de 1990, podem ter continuado a influenciar a desindustrialização brasileira no período mais recente - após ano 2000 - einfluenciado ao aumento das exportações de produtos de menor valor agregado como commodities. Ademais, os custos industriais podem também ser um grande determinante para a desindustrialização no período e vem ganhando importância na literatura recente. Pastore (2012) afirma que o aumento dos custos industriais pode decorrer de um aquecimento do setor de serviços, já que o salário neste setor aquecido acaba por aumentar o salário no setor industrial. O problema decorre do fato de a produtividade não ter um correspondente aumento para manter o Custo Unitário do Trabalho ${ }^{4}$ constante. Segundo a CNI (2016) após outubro de 2002 os custos industriais apresentaram tendência crescente

Outro determinante que passou a reter o foco de pesquisas relacionadas as estruturas produtivas a partir da década de 2000, fora o efeito do crescimento elevado da China, um país que tem como foco o crescimento baseado em seu comércio internacional. Neste caso, a China acabou por gerar divisão do trabalho e consequentemente especialização produtiva (Puga 2005). Essa especialização produtiva pode contribuir para o agravamento do efeito chamado "desindustrialização".

O "Efeito China" pode ser caracterizado como o aumento dos preços das commodities, ocasionado pela elevada demanda chinesa por matérias primas e pela queda dos preços de produtos manufaturados, devido ao aumento da oferta destes bens por aquele país. Para Acioly, Pinto e Cintra (2011) o acirramento no comércio entre Brasil e China gera externalidades sobre o parque industrial brasileiro, gerando: 1) Especialização regressiva da pauta exportadora brasileira;

4 Segundo Bonelli (2012), o CUT pode ser definido como à razão entre o salário médio real e a produtividade do trabalho. O indicador é altamente usado como uma medida de competitividade internacional. 
2) Déficit para o Brasil em produtos de alta intensidade tecnológica; 3) Penda de participação em terceiros mercados em produtos de maior intensidade tecnológica.

Cabe mencionar ainda que a maneira com que a taxa de câmbio é determinada em países que apresentam elevada dependência de exportações de produtos básicos e commodities tende a ser diferente dos países que baseiam suas exportações em produtos manufaturados. Espera-se que a flutuação do preço das commodities possa influenciar na determinação da taxa de câmbio em países que baseiam suas exportações em commodities (Fernandez 2003).

Os modelos que buscam determinar a taxa de câmbio partem do pressuposto de que no longo prazo a PPC $^{5}$ não é válida, desta forma, a taxa de câmbio real dependeria também de fatores reais (VERÍSSIMO et al. 2010). Assim, diversos autores passaram a estudar o não ajustamento da taxa de câmbio para manter uma PPC constante, dentre eles destacam-se, principalmente, Gregorio e Wolf (1994), Froot e Rogoff (1995) e Rogoff (1996). Nessa linha, Chen e Rogoff (2002) incluem o preço das commodities como um dos determinantes da taxa de câmbio em países com elevada dependência de exportações de commodities, sendo que uma variação do mesmo poderia causar um choque real na taxa de câmbio. Afirma-se que países com essa característica apresentam o que se convencionou chamar commodity currency.

A partir do referencial teórico apresentado, o presente estudo busca responder as seguintes questões: Em que montante o aumento da taxa de câmbio poderia modificar o saldo da balança comercial Paranaense de produtos básicos? Segundo os autores que defendem a à doença holandesa no Brasil, uma taxa de câmbio mais depreciada favoreceria a balança comercial de setores com maior valor agregado, porém, é necessário visualizar o que ocorre com as balanças de produtos básicos, principalmente em um estado que depende grandemente das exportações desses produtos. Além disso, de que maneira a balança comercial Paranaense, seria afetada pelo aumento da renda mundial, ou seja, estaria o estado do Paraná sendo impactado pelo Efeito-China? A próxima seção traz alguns estudos empíricos que buscaram compreender a dinâmica do comércio exterior paranaense, com destaque para análises da balança comercial do estado.

\section{a. TRABALHOS EMPÍRICOS SOBRE A BALANÇA COMERCIAL} PARANAENSE

São relativamente escassos os trabalhos com objetivo de estudar a balança comercial do estado do Paraná, mesmo considerando todas as suas nuances. Dos estudos realizados sobre o tema alguns poucos trabalhos se destacam como o de Nakabashi e Cruz (2007), Souza (2003), Schmidtke e Braun (2006) e Caldarelli, Camara e Sereia (2009).

5 A teoria da Paridade de poder de compra afirma que bens mensurados em uma mesma moeda devem apresentar o mesmo nível de preço. Para isso a taxa de câmbio automaticamente se ajustaria a diferença entre os níveis de preços entre os países (Dornbusch 1975). 
Nakabashi e Cruz (2007) analisam o efeito da taxa de câmbio e dos juros através de uma regressão sobre as exportações e importações paranaenses entre os anos de 2001 e 2006. Segundo os autores a taxa de câmbio estaria provocando pressões sobre o setor exportador e estimulando as importações. Da mesma maneira, a taxa de juros também se mostrou como uma importante variável sobre o setor exportador, tendo sua redução impactado positivamente as exportações no período.

Souza (2003) analisa os efeitos da abertura comercial brasileira sobre o crescimento, além das relações entre exportações e importações com o PIB e emprego. Os autores mostram que no período de 1991 a 2000 o estado do Paraná deteve o quinto maior saldo comercial, se apresentando como o sexto estado mais aberto ao comércio internacional no período. Além disso, por meio da pesquisa, os autores chegam à conclusão de que o Paraná é o estado que apresentou a maior correlação de comércio externo com o PIB e emprego.

Já os autores Schmidtke e Braun (2006) avaliaram o desempenho dos produtos agrícolas e agroindustriais brasileiros e paranaenses no mercado internacional, com ênfase para as restrições comerciais impostas pelos países desenvolvidos. Os autores explanam que sendo a soja o principal produto exportado pelo estado do Paraná, os subsídios oferecidos pelos Estados Unidos e União Europeia dificultam a entrada de empresas paranaenses exportadoras desse produto. Os autores também chamam à atenção para o protecionismo realizado pela China nos produtos derivados da soja, como, por exemplo, o óleo. O estudo conclui que o Paraná perdeu participação na pauta exportadora no período estudado.

Por fim, Caldarelli, Camara e Sereia (2009) analisam o comportamento das exportações de soja e derivados, para o Brasil e Paraná, no período de 1990 a 2007 por meio de um modelo de Constant Market Share (CMS). Os autores afirmam que o complexo soja foi um importante gerador de divisas para o país e que o estado do Paraná foi o segundo maior exportador desse complexo. Os autores afirmam quea isenção de ICMS (lei Kandir) para a exportação debens "in natura" em complementariedade às barreiras protecionistas utilizadas por outros países fizeram com que o Brasil se especializasse na produção dos grãos. Além disso, os autores verificaram que o estado apresentou elevado ganho de competitividade e Market-share no período, influenciados ainda pela abertura comercial após 1990.

Dado exposto, o presente estudo busca complementar os até então realizados, detalhando os impactos de curto e longo prazo, na balança comercial dos bens básicos do Paraná, das variações cambiais e da renda externa. Justifica-se o presente, porquanto a temática ainda carece de maiores contribuições empíricas para que se possa avançar na compreensão dos determinantes do comércio exterior de básicos no estado. Este estudo busca aclarar a questão do comércio exterior de bens básicos do estado e a relevância dos fatores de influência câmbio e renda externa. Os esforços deste trabalho vão no sentido de ampliar o debate acerca de uma trajetória de reprimarização da pauta do estado.

\section{METODOLOGIA}


O presente estudo utiliza as variáveis explicativas: taxa de câmbio e renda estrangeira como deslocadores da demanda de exportações. Assim como Bahmani-Oskooee e Xu (2012), a taxa de câmbio nominal foi escolhida em detrimento da taxa de câmbio real, já que a primeira reflete a relação de troca entre moedas. Desta forma, ao utilizar a taxa de câmbio nominal, espera-se que os efeitos no balanço de pagamentos sejam analisados de forma mais eficiente quando se trata de analisar a política cambial e sua efetividade.

Para tanto, definiu-se que a balança comercial de produtos básicos do estado do paraná é uma função da renda do estrangeiro e da taxa de câmbio nominal. Desta forma, o modelo teórico empregado na análise pode ser descrito por:

$\ln B C B=\beta_{0}+\beta_{1} \ln C+\beta_{2} \ln P I B M+\mu_{t}$

(3)

Em que $\operatorname{lnBCB}$, lnC, e lnBCBIM são os logaritmos naturais da razão X-M para a categoria básicos de fator agregado; lnC é o logaritmo natural da taxa de câmbio nominal e lnPIBM é o logaritmo natural do PIB mundial; $\beta_{0}, \beta_{1}$ e $\beta_{2}$ são os coeficientes a serem estimados da equação de longo prazo entre as variáveis e $\mu_{t}$ é o termo de erro.

Para atingir o objetivo proposto da estimação dos coeficientes, utilizou-se a metodologia padrão de séries temporais, ou seja, verificou-se primeiramente se as séries são estacionárias ou integradas de ordem (0), para isso utilizou-se os testes $\mathrm{ADF}$ e DF-GLS. Para determinar o número de defasagens, utiliza-se o critério de Akaike (AIC).

Posteriormente, sendo as séries não estacionárias é realizado o teste de J ohansen (1988) para verificar a existência de cointegração entre as variáveis, por meio da estatística traço $\lambda$. Se as séries forem cointegradas, ou seja, apresentarem uma relação estável de longo prazo, é possível estimar um modelo vetorial de correção de erro (VECM), com o intuito de estimar os coeficientes da equação (3).

A partir de J ohansen (1988), o modelo vetorial de correção de erros (VECM) pode ser decomposto em:

$\Pi=\alpha \beta^{\prime}$

Onde o posto da matriz $\Pi$ define o número de vetores de cointegração e $\alpha$ representa a velocidade de ajustamento ou o coeficiente de ajuste de curto prazo e $\beta^{\prime}$ é uma matriz de coeficientes de cointegração; coeficientes de longo prazo.

\subsection{BASE DE DADOS}

Este estudo utilizou dados de importação e exportação do Paraná do MDIC/ SECEX, para a série de Câmbio nominal os dados da taxa de Câmbio PTAX 
foram obtidos junto ao sítio do BACEN. Com relação ao PIB do mundo, dados do FMI Data foram coletados.

\section{RESULTADOS E DISCUSSÃO}

Na presente seção apresentam-se os resultados do modelo empírico e a discussão dos resultados encontrados. Precedeà análise dos resultados do modelo empírico - modelo VEC - a verificação acerca da estacionariedade das séries utilizadas assim como teste de validação da hipótese de cointegração entre as mesmas.

As Tabelas 1 e 2, na sequência, apresentam os resultados dos testes de raiz unitária utilizados neste estudo, respectivamente, Augmented Dickey-Fuller e Dickey-Fuller Generalized Least Square. Em ambos os testes o número de defasagens utilizadas foi determinado pelo Critério de Informação de Akaike Modificado (MAIC).

Tabela 1 - Resultados dos testes de raiz unitária - ADF - com e sem tendência para as séries (em nível) utilizadas no modelo

\begin{tabular}{llll}
\hline Variável & Tendência & $\mathrm{P}$ & Estatística ADF \\
\hline \multirow{2}{*}{$\operatorname{lnBCB}$} & Não & 6 & $-3.082278^{* *}$ \\
& Sim & 4 & $-7.245154^{*}$ \\
\hline \multirow{2}{*}{$\ln \mathrm{Não}$} & 1 & -1.275879 \\
& Sim & 1 & -1.188064 \\
\hline \multirow{2}{*}{$\ln$ NIBM } & Não & 6 & -1.450799 \\
& Sim & 6 & -1.797367
\end{tabular}

* Significativo à 1\% de significância, ** significativo a 5\% de significância, *** significativo a 10\% de significância.

H0: Presença de raiz unitária; H1: Ausência de raiz unitária.

Tabela 2 - Resultados dos testes de raiz unitária - DF-GLS- com e sem tendência para as séries (em nível) utilizadas no modelo.

\begin{tabular}{llll}
\hline Variável & Tendência & $\mathrm{P}$ & Estatística ADF \\
\hline \multirow{2}{*}{$\ln B C B$} & Não & 6 & -1.167238 \\
& Sim & 3 & $-6.688746^{*}$ \\
\hline \multirow{2}{*}{$\ln C$} & Não & 1 & -0.547810 \\
& Sim & 1 & -1.327793 \\
\hline \multirow{2}{*}{$\ln$ NIBM } & Não & 6 & 0.108378 \\
& Sim & 6 & -1.930655
\end{tabular}

* Significativo à 1\% de significância, ** significativo a 5\% de significância, *** significativo a 10\% de significância.

H0: Presença de raiz unitária; H1: Ausência de raiz unitária. 
Os resultados apresentados permitem inferir que para a série lnBCB rejeita-se a hipótese nula de que ela apresente raiz unitária sob a análise do teste ADF (Tabela 1), já através do teste DIF-GLS (Tabela 2), rejeita-se a hipótese nula apenas com tendência. Por outro lado, para as séries LnC e LnPIBM, não se pode rejeitar a hipótese nula de que há nelas uma raiz unitária em ambos os testes (Tabelas 1 e 2), inferindo assim, que as séries são não estacionárias.

Verificada a ordem de integração das variáveis - em que todas podem ser consideradas como I(1) -, faz-se necessário, na sequência, a seleção de defasagens a serem utilizadas no modelo, para a operacionalização da análise de cointegração e obtenção dos resultados do modelo VEC. Para tal, foram utilizados os resultados sumarizados na Tabela 3, que sinalizam a utilização de quatro defasagens, uma vez que este é o valor apontado pela maioria dos critérios de seleção.

Tabela 3 - Diferentes critérios para seleção de defasagens

\begin{tabular}{lllllll}
\hline Lag & Df & $\mathrm{p}$ & FPE & AIC & HQIC & SBIC \\
\hline 0 & - & - & 0.004376 & 3.08 & 3.10 & 3.14 \\
1 & 9 & 0.000 & $4.3 \mathrm{e}-06$ & -3.84 & -3.76 & -3.63 \\
2 & 9 & 0.000 & $3.1 \mathrm{e}-06$ & -4.18 & -4.03 & $-3.81^{*}$ \\
3 & 9 & 0.000 & $2.7 \mathrm{e}-06$ & -4.31 & $-4.09^{*}$ & -3.77 \\
4 & 9 & 0.005 & $2.6 \mathrm{e}-06^{*}$ & $-4.34^{*}$ & -4.05 & -3.64 \\
5 & 9 & 0.071 & $2.7 \mathrm{e}-06$ & -4.32 & -3.98 & -3.47 \\
6 & 9 & 0.484 & $2.8 \mathrm{e}-06$ & -4.27 & -3.86 & -3.26 \\
\hline
\end{tabular}

Fonte: Elaborado pelos autores a partir dos dados da pesquisa.

Observação: $\mathrm{FPE}=$ Erro de previsão final, $\mathrm{AIC}=$ critério de informação de Akaike, $\mathrm{AIC}=$ Critério de informação bayesiano de Schwarz e HQIC= Estatística de seleção de ordem de defasagens para vetores autoregressivos de primeira ordem.

Concernenteà cointegração entre as séries utilizadas nesteestudo, pode-seinferir que as mesmas apresentam relação estável de longo prazo, ou seja, são cointegradas. Os resultados do teste de J ohansen (Tabela 4) sinalizam que as variáveis possuem um vetor de cointegração, uma vez que a estatística traço mostra-se significativa em relação ao valor crítico de 5\%. Para analisar essa relação em termos de elasticidades, porquanto as variáveis estão em logaritmo, utilizou-se um modelo do tipo VEC, cujos resultados estão dispostos na Tabela 5. 
Tabela 4 - Teste de cointegração deJ ohansen para as variáveis do Modelo.

\begin{tabular}{lllll}
\hline $\begin{array}{l}\text { Hipótese } \\
\text { nula }\end{array}$ & $\begin{array}{l}\text { Hipótese } \\
\text { alternativa }\end{array}$ & Eigenvalue & Traço & Valores críticos (5\%) \\
\hline $\mathrm{r}=0$ & $\mathrm{r}>0$ & - & 61.9716 & 34.91 \\
$\mathrm{r} \leq 1$ & $\mathrm{r}>1$ & 0.24134 & $11.7026^{*}$ & 19.96 \\
$\mathrm{r} \leq 2$ & $\mathrm{r}>2$ & 0.05057 & 2.2575 & 9.42 \\
$\mathrm{r} \leq 3$ & $\mathrm{r}>3$ & 0.01233 & - & - \\
\hline
\end{tabular}

Fonte: Elaborado pelos autores a partir dos dados da pesquisa.

A relação de longo prazo apresentada pela equação cointegradora do modelo estimado (Tabela 5) traz algumas informações relevantes ao estudo da sensibilidade da Balança Comercial de bens básicos no Paraná em relação a variações cambiais e movimentos na demanda mundial, analisada neste artigo com o uso da proxy PIB mundial, sobretudo com relação as elasticidades câmbio e renda externa da Balança comercial do Paraná.

Tabela 5 - Estimativas dos coeficientes de curto elongo prazo do modelo Vetorial de Correção de Erros (VEC)

\begin{tabular}{cccc}
\hline Variável & $\begin{array}{c}\text { Coeficientes de ajuste de } \\
\text { curto prazo } \alpha\end{array}$ & $\begin{array}{c}\text { Coeficientes de longo prazo } \\
\beta\end{array}$ & p-value \\
\hline $\ln B C B$ & $-0,6688$ & 1 & - \\
$\ln C$ & 0,0002 & 1,3873 & 0,000 \\
$\ln$ PIBM & 0,0102 & 1,8128 & 0,000 \\
Constante & - & 5,4168 & 0,001 \\
\hline
\end{tabular}

Fonte: Elaborado pelos autores com dados da pesquisa

Nota: Os resultados dos coeficientes de longo prazo ( $\beta$ ) são apresentados com sinais invertidos devido à normalização do vetor de cointegração.

Para tanto, apresentam-se os coeficientes de longo prazo $(\beta)$ em forma de equação, como segue:

$\ln B C B=5,41+1,38 \ln C+1,81 \ln P I B M$

Inicialmente, destaca-se que o valor 1,38 para o coeficiente da variável câmbio indica que a Balança Comercial paranaense de bens básicos é sensível a variações cambiais, porquanto tal coeficiente sinaliza uma relação elástica na transmissão câmbio-balança comencial. O resultado mostra que dada uma variação no câmbio de 1\%, aproximadamente 1,38\% dessa variação étransmitidaà Balança Comercial de bens básicos do estado do Paraná, ou seja, trata-se de uma transmissão mais que proporcional - elástica em relação ao câmbio. 
Do resultado em questão um ponto importante cabe ser detalhado; a questão da relevância das flutuações cambiais e da política cambial sobre a Balança Comercial dos básicos no Paraná. Como ressaltado anteriormente o resultado da balança comercial de básicos no estado do Paraná corresponde a 2,76 o resultado da balança geral e como ressaltado pelos resultados uma depreciação cambial implicaria em saldos superiores sobre a balança comercial. De acordo com os teóricos da doença holandesa brasileira, uma taxa de câmbio depreciada estimularia setores mais intensivos em capital, porém, como verificado a balança comercial de produtos básicos também atrairia recursos.

Concernente à variável PIB mundial, utilizada neste estudo como proxy para demanda mundial, o coeficiente estimado no modelo VEC (Tabela 5) indica que a Balança Comercial de bens básicos no Paraná é elástica em relação às variações desta variável. Ao considerar uma variação de $1 \%$ no PIB mundial verifica-se que a balança comercial do estado varia em torno de 1,81\% desta, assim, a expansão do fluxo da produção mundial (PIB) reflete no fluxo de comércio externo de bens básicos do Paraná.

Chama a atenção neste resultado a importância do crescimento da produção mundial (PIB) para o fluxo de comércio de bens básicos no Paraná; cabe destacar que fatores exógenos como a crise dos EUA, observada em 2007/ 08, e o chamado "Efeito China" afetariam a balança comercial de produtos básicos no estado de maneiras distintas. O primeiro determinaria a queda das exportações dos produtos básicos pela consequente queda da demanda mundial, já o segundo, levando em conta a continuidade do crescimento chinês, atuaria no sentido de direcionar a produção do estado para produtos agropecuários e de menor valor agregado, uma vez que a demanda e consequentemente o preço destes produtos aumentaria. Este fenômeno pode aprofundar o processo de mudanças na estrutura produtiva, e melhorar o resultado desta balança comercial.

Os resultados dos coeficientes de curto prazo (a) mostram que os ajustes nos desequilíbrios na Balança Comercial de bens básicos do Paraná apresentam velocidade de ajustamento relativamente rápida - cerca de 66,8\% em cada período - , ou seja, um desequilíbrio ajusta-se em menos de 2 períodos; o sinal desse coeficiente, como esperado é negativo. Com relação às variáveis câmbio e PIB mundial os sinais dos coeficientes foram positivos, o que reforça a ideia de exogeneidade para tais séries.

Com vistas ao exame dos efeitos dinâmicos do modelo estimado, apresenta-se, nas Figuras 1e 2, a trajetória das funções de impulso-resposta da variável LnBCB frente a choques não antecipados - de magnitude de um desvio-padrão - nas variáveis LnC e LnPIBM, respectivamente.

O comportamento da variável LnBCB frente a um choque não antecipado na variável LnC - equivalente a uma desvalorização cambial - mostra três fases distintas (Figura 3). Em um primeiro momento, observa-se uma redução dos saldos da BC, fato sustentado pelo efeito de rigidez de contratos no curto prazo e com aporte teórico da chamada curva J ${ }^{6}$. Uma segunda fase advém do "efeito

6 Efeito verificado após uma depreciação cambial, desta maneira o preço das importações aumenta devido à depreciação, porém a quantidade permanece constante, uma vez que contratos estão fixos, aumentando o valor das importações totais. Além disso, o preço das exportações se 
competitividade" que o câmbio confere às exportações, tornando-as mais baratas relativamentee, consequentemente, aumentando o saldo da BC. Esse efeito torna visível o impacto das desvalorizações cambiais sobre as exportações de bens básicos no Paraná. Por fim, uma terceira fase pode ser identificada na trajetória da variável $\operatorname{LnBCB}$, após 15 meses do choque, a saber, a estabilização da respectiva balança. Cumpre destacar que a estabilização dessa variável póschoque se localiza em um patamar superior àquele anterior ao choque, convergente ao conceito de histerese descrito por Kannebley J unior, Prince e Scarpelli (2011).

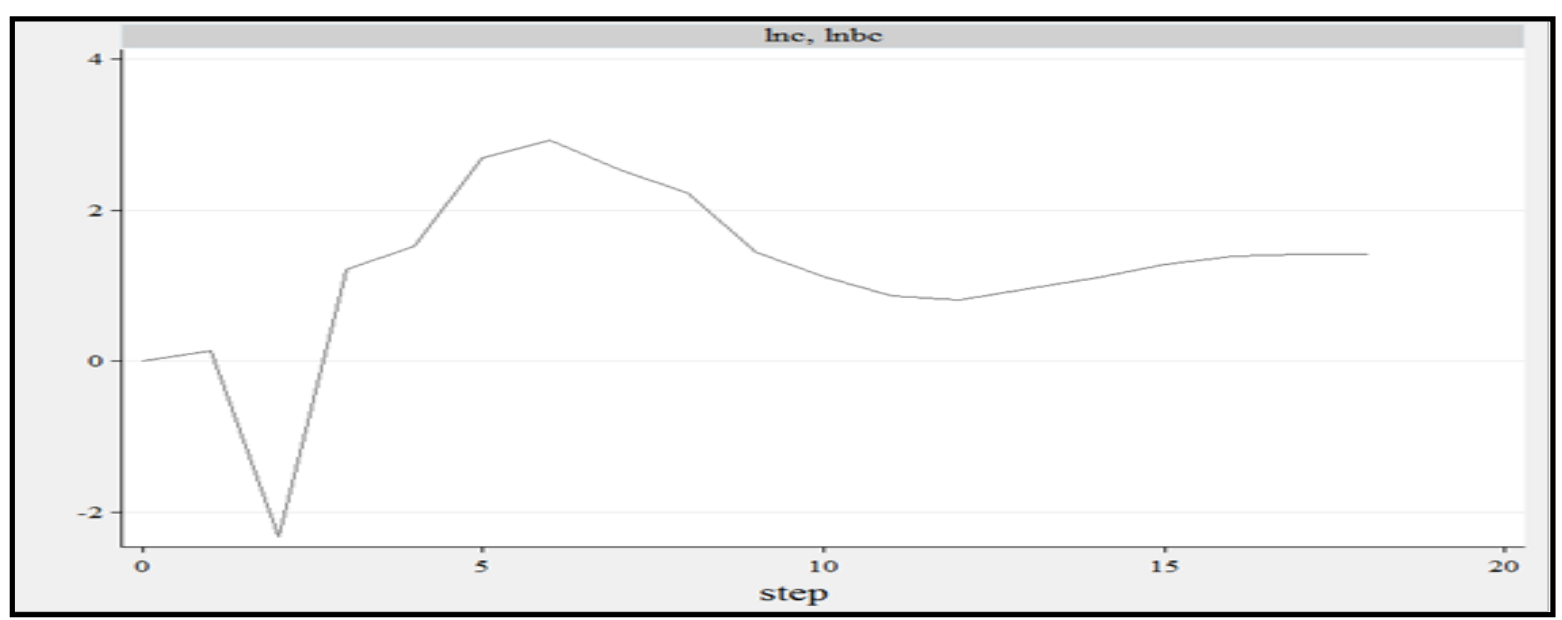

Figura 3 - Trajetória da Balança Comercial de bens Básicos no Paraná frente a um choque não antecipado na taxa de câmbio - 18 períodos à frente.

Fonte: Elaborado pelos autores com dados da pesquisa

Nota: A resposta ao impulso do modelo foi obtida pelo método GIR - função de impulso-resposta generalizada.

O PIB mundial, tomado como choque não antecipado, também desempenhou efeito considerável sobre a variável LnBCB (Figura 4), cuja trajetória pode ser analisada em quatro momentos distintos. O primeiro deles, imediato pós-choque, destaca-se como elevação do saldo da BC, decorrente de aumentos nos fluxos de comércio exterior advindos da maior renda externa. Na sequência, um segundo momento pode ser identificado, em que a variável LnBCB reverte a trajetória de elevação e apresenta queda, movimento que pode ser explicado pela maior concorrência pós-choque, em que outros fornecedores de bens básicos possam intensificar também suas exportações. Uma terceira fase pode ser observada 12 períodos após o choque, em que os saldos da Balança Comercial de básicos no Paraná apresentam elevação contínua até se estabilizar, por volta do 16 períodos pós-choque.

reduz, porém, no curtíssimo prazo a demanda permanece constante, diminuindo as receitas de exportações. (Sonaglio, Scalco, Campos 2010). Com o tempo, a balança comercial começa a apresentar resultados positivos superiores aos anteriores à depreciação representando graficamente algo semelhante a uma letra J. 
Fato relevante que deve ser salientado é a estabilização pós-choque, da trajetória da variável LnBCB frente a aumento exógeno da renda externa, que se dá a um patamar superior àquele observado pré-choque. Neste caso, pode-se salientar que os efeitos do aludido choque desempenham impactos de longo prazo permanentes sobre a trajetória da variável em questão. À vista disso, pode-se inferir, portanto, que um choque adverso concernente à redução da renda externa também desempenha efeitos de longo prazo duradouro na variável em questão - LnBCB , contudo, de forma contrária.

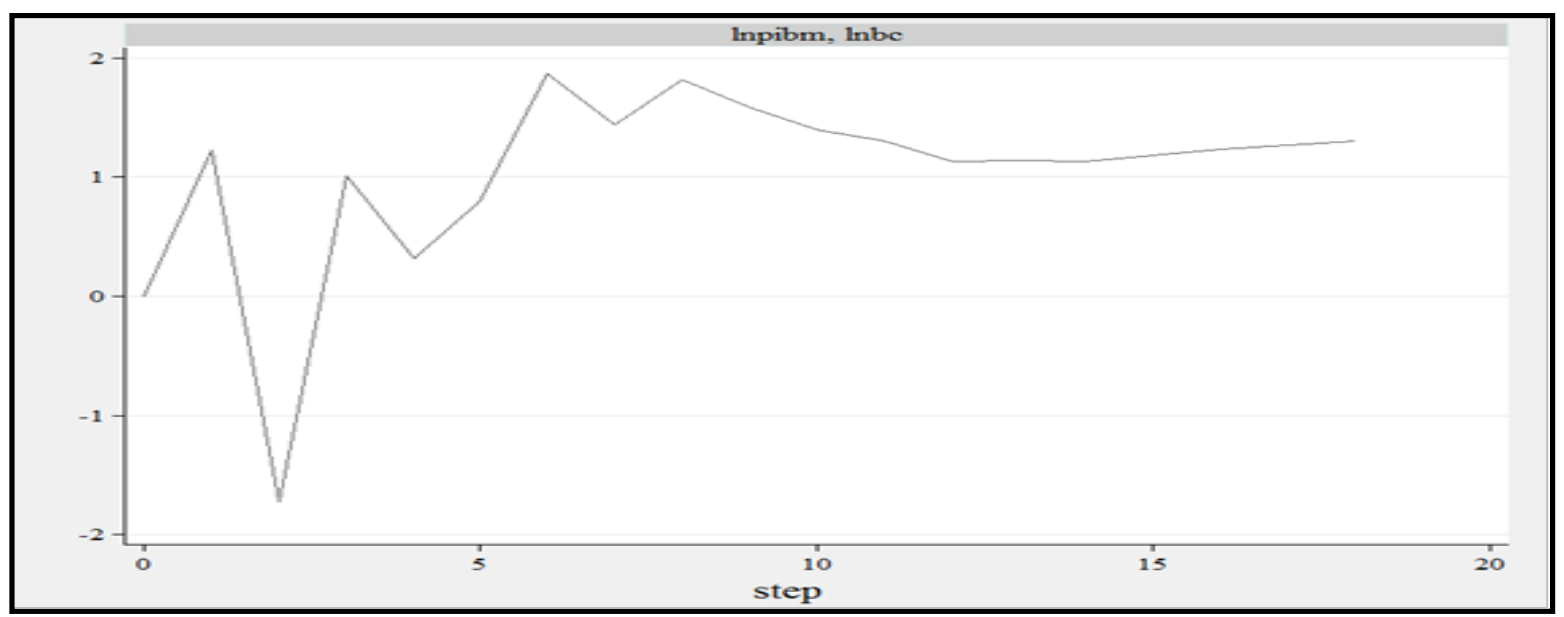

Figura 4 - Trajetória da Balança Comercial de bens Básicos no Paraná frente a um choque não antecipado em PIB mundo - 18 períodos à frente.

Fonte: Elaborado pelos autores com dados da pesquisa

Nota: A resposta ao impulso do modelo foi obtida pelo método GIR - função de impulso-resposta generalizada

Para medir a importância relativa de cada variável do sistema na variância da variável lnBCB, realizou-se a decomposição da variância dos erros de previsão. Assim, cerca de $85 \%$ da variância dos erros de previsão da variável lnBCB é explicada pela própria $\ln B C B$, lnC e lnPIBM explicam respectivamente $7 \%$ e $8 \%$ da variância do erro de previsão, assim a renda mundial apresenta maior importância para a balança comercial dos produtos básicos do estado do Paraná que o câmbio. 
Tabela 6. Decomposição da variância dos erros de previsão de lnBCB.

\begin{tabular}{llll}
\hline Período & $\operatorname{lnBCB}$ & LnC & $\ln$ PIBM \\
\hline 1 & 1 & 0 & 0 \\
2 & 0.9944 & 0.0003 & 0.0053 \\
3 & 0.9690 & 0.0106 & 0.0204 \\
4 & 0.9665 & 0.0113 & 0.0221 \\
5 & 0.9636 & 0.0143 & 0.0221 \\
6 & 0.9514 & 0.0260 & 0.0226 \\
7 & 0.9332 & 0.0367 & 0.0299 \\
8 & 0.9208 & 0.0453 & 0.0339 \\
9 & 0.9081 & 0.0508 & 0.0411 \\
10 & 0.9012 & 0.0526 & 0.0462 \\
11 & 0.8968 & 0.0534 & 0.0498 \\
12 & 0.8937 & 0.0536 & 0.0527 \\
13 & 0.8916 & 0.0537 & 0.0546 \\
14 & 0.8891 & 0.0542 & 0.0566 \\
15 & 0.8862 & 0.0552 & 0.0586 \\
16 & 0.8825 & 0.0566 & 0.0609 \\
17 & 0.8782 & 0.0584 & 0.0634 \\
18 & 0.8737 & 0.0602 & 0.0661 \\
19 & 0.8691 & 0.0620 & 0.0689 \\
20 & 0.8647 & 0.0636 & 0.0717 \\
21 & 0.8606 & 0.0650 & 0.7438 \\
22 & 0.8568 & 0.0662 & 0.0770 \\
23 & 0.8531 & 0.0674 & 0.0795 \\
24 & 0.8495 & 0.0686 & 0.0819 \\
\hline
\end{tabular}

Fonte: Resultados da pesquisa.

Ademais, cabe salientar que está disposto no apêndice na Tabela A1, o teste de multiplicador de Lagrange para identificação de autocorrelação. Dela é possível observar que não se rejeita a hipótese nula de ausência de autocorrelação até a quarta defasagem, demonstrando assim, que o modelo é significativo. Além disso, o apêndice também dispõe do círculo unitário da condição de estabilidade dos autovalores dos vetores autoregressivos.

\section{CONSIDERAÇÕES FINAIS}

Como verificado pelo estudo, a balança comercial de produtos básicos no estado do Paraná contribui positivamente para que o estado apresente superávit na balança comercial. Dada a importância destes produtos, o presente estudo teve 
por objetivo analisar a renda externa e a taxa de câmbio nominal como seus determinantes.

Os resultados apontam que a balança comercial de produtos básicos do estado do Paraná é elástica tanto em relação ao câmbio quanto renda externa. Além disso, o efeito do câmbio sobre a pauta exportadora brasileira é ambíguo, uma vez que segundo teóricos da doença holandesa esta viabilizaria setores de maior valor agregado, porém, de acordo com os resultados também melhoraria o saldo da balança de produtos básicos o que poderia gerar disputa de recursos entre os setores.

Por outro lado, fica um pouco mais claro que o crescimento mundial, sustentado principalmente pela China, poderia estar causando especialização regressiva da pauta exportadora brasileira, uma vez que o aumento na renda mundial se transmite mais que proporcionalmente para a Balança comercial de bens básicos do Paraná.

Este estudo permite inferir que a o câmbio nominal e a renda externa são dois determinantes relevantes da Balança Comercial dos bens básicos no Paraná. Essa constatação destaca que desvalorizações cambiais e efeitos de crescimento externo acelerado, como o chamado "Efeito China", podem levar a melhoras nos saldos da BC dos básicos. Essa constatação enseja uma discussão mais intensa acerca dos mecanismos de agregação de valor às exportações do Estado e diversificação da pauta, discussões fora do escopo deste estudo, contudo apontados como relevante para estudos futuros.

Por fim, cabe destacar que em futuras pesquisas também será avaliado quanto o aumento do PIB paranaense impacta na balança comercial de produtos básicos. Além disso, buscar-se-á expandir a pesquisa para as demais denominações de fator agregado, ou seja, para os semimanufaturados e manufaturados.

\section{REFERÊNCIAS}

ACIOLY, L.; PINTO, E. C.; CINTRA, M. A. M. China e Brasil: oportunidades e desafios. A China na Nova Configuração Global: impactos políticos e econômicos. Brasília: IPEA, p. 325-350, 2011.

BAHMANI-OSKOOEE, M.; XU, J . Is there evidence of the j-curve in commodity trade between the USA and Hong Kong? The Manchester School, vol. 80, No. 3, p. 295-320, 2012.

BONELLI, R.; PESSOA, S. D. A.;. Desindustrialização no Brasil: Um Resumo da Evidência. Texto para Discussão, Rio deJ aneiro: FGV-IBRE, n. 7, mar. 2010. Disponível em:

http:/ / bibliotecadigital.fgv.br/ dspace/ bitstream/ handle/ 10438/ 11689/ Desindu strializa\%C3\%A7\%C3\%A30\%20no\%20Brasil.pdf?sequence=1. Acesso em: 14 dez. 2016. 
BRESSER P. L. C. Doença holandesa e sua neutralização: uma abordagem ricardiana. In: Luiz Carlos Bresser-Pereira. (Org.). Doença holandesa e indústria. led.Rio de Janeiro: Editora FGV, 2010, v. 1, p. 117-154.

BRESSER P. L. C.; MARCONI, N. Existe Doença Holandesa no Brasil?. In: $4^{\circ}$ Fórum de Economia, 2008, São Paulo. Disponível em: http:// www.bresserpereira.org.br/ papers/2008/08.14.Existe.doen\%C3\%A7a.h olandesa.com Nelson.Marconi.5.4.08.pdf. Acesso: 18 dez. 2016.

CALDARELLI, C. E; CAMARA, M. R. G.; SEREIA, V. J . O Complexo Agroindustrial da Soja no Brasil e no Paraná: Exportações e Competitividade no período de 1990 a 2007. Organizações Rurais e Agroindustriais (UFLA), v. 11, p. $1-20,2009$.

ROGOFF, K; CHEN, Y. C.. Commodity currencies and empirical exchange rate puzzles. International Monetary Fund, 2002.

CNI (2016), Confederação Nacional da Indústria - CNI. Custo do trabalho e produtividade: Comparações internacionais e recomendações. Disponível em: http:// www.portaldaindustria.com.br/ relacoesdotrabalho/media/ o portal/Cus to\%20do\%20trabalho\%20e\%20produtividade.pdf. Acesso em: 16 jan. 2017.

GREGORIO, J. D.; WOLF, H. Terms of Trade, Productivity and the Real Exchange Rate. Cambridge, Massachusetts. NBER Working Paper No. 4807, July, 1994.

DORNBUSCH, R. Exchange rates and fiscal policy in a popular model of international trade. American Economic Review, 65 (5), Dec. 1975.

OREIRO, J . L.; FEIJ Ó, C. A. Desindustrialização: conceituação, causas, efeitos e o caso brasileiro. Revista de Economia Política, São Paulo, v.30, n.2 (118), p. 219-232, abr./jun. 2010.

FERNANDEZ, C. Y. H. Câmbio Real e Preços de Commodities: Relação Identificada Através da Mudança de Regime Cambial. Rio deJ aneiro. Dissertação de Mestrado. Pontifícia Universidade Católica. Departamento de Economia. 86p. 2003.

FERREIRA, A. H. B.. Testes de Granger-causalidade para a balança comercial brasileira. Revista Brasileira de Economia, Rio de J aneiro, v. 47, n.1, p. 83-95, 1993.

FROOT, K.; ROGOFF, K. Perspectives on PPP and Long-Run Real Exchange Rates. In: GROSSMAN, G. \& ROGOFF, K. (eds.) Handbook of International Economics, pp. 1647-88. Ed. Elsevier Science B. V., 1995. 
IBGE (2016), INSTITUTO BRASILEIRO DE GEOGRAFIA E ESTATÍSTICA. Pesquisa Mensal do Emprego - PME. Disponível em http://www.ibge.gov.br>. Acesso em: 18 jan. 2017.

IPEADATA (2016), Instituto de Pesquisa Econômica Aplicada - IPEA. Disponível em: http:// www.ipeadata.gov.br/. Acesso em: 18 jan. 2017.

J OHANSEN, S. Statistical analysis of cointegration vectors. J ournal of Economic Dynamics and Control, v.12, p.231-254, 1988.

KANNEBLEY JUNIOR, S; PRINCE, D de; SCARPELLI, M C. Histerese e o comércio exterior de produtos industrializados brasileiros. Pesquisa e Planejamento Econômico: PPE, vol. 41, No. 3, p. 397-432, Dezembro 2011.

KRUEGER, A. Exchange rate determination. Cambridge: Cambridge University Press, 1983.

LERNER, A. P. (1944). The Econonomics of control: Principles of Welfare Economics. The Macmillan Company, N. Y.

MARSHALL, A. (1923). Money, Credit and Commerce. Macmillan, London.

MINISTÉRIO DA INDÚSTRIA, COMÉRCIO EXTERIOR E SERVIÇOS. Base de dados do comércio exterior brasileiro. Disponível em:

http:/ / www.mdic.gov.br/ comercio-exterior/ estatisticas-de-comercioexterior/ base-de-dados-do-comercio-exterior-brasileiro-arquivos-paradownload. Acesso em: 14 de fev, 2017.

MOURA, G. V. Condição de Marshall Lerner e Quebra Estrutural na Economia Brasileira. [dissertação]. Porto Alegre: Universidade Federeal do Rio Grande do Sul, mestrado em Economia, 2005.

NAKABASHI, L.; CRUZ, M. J . V.. OS EFEITOS DO CÂMBIO E J UROS NA BALANÇA COMERCIAL PARANAENSE. In: V Encontro de Economia Paranaense, 2007, Curitiba. V Encontro de Economia Paranaense. Curitiba, 2007.

NASSIF, A. Há evidências de desindustrialização no Brasil?. Revista de Economia Política, São Paulo, v. 28, n. 1(109), p. 72-96, jan./ mar. 2008.

PASTORE, A. C. Por que a indústria parou de crescer nos últimos anos? In: O Estado de São Paulo, 2012, São Paulo.

PUGA, P.F. A inserção do brasil no comércio mundial: o efeito china e potenciais de especialização das exportações. 68f. Texto para discussão 106. Banco Nacional de Desenvolvimento Econômico e Social. Rio de J aneiro, 2005. 
ROGOFF, K. The Purchasing Power Parity Puzzle. J ournal of Economic Literature, N. 2, Vol. 34, pp. 647-68, J une, 1996.

SCHMIDTKE, C. R.; BRAUN, M. B. S. . A Agricultura Brasileira no Comércio Internacional: O Caso do Paraná. In: XLIII Congresso da Sociedade Brasileira de Economia e Sociologia Rural, 2005, Ribeirão Preto. Instituições, Eficiência, Gestão e Contratos no Sistema Agroindustrial. RIBEIRÃO PRETO:

FEARP/USP, PENSA/USP, 2005. p. 1-331.

SONAGLIO, C. M.; SCALCO, P. R.; CAMPOS, A. C. Taxa de Câmbio e a Balança Comercial Brasileira de Manufaturados: Evidências da J-Curve. Revista Economia, vol. 11, No. 3, p. 711- 734, setembro/ dezembro 2010.

SOUZA, G. J . G.; BASILIO, F. A. C.; OREIRO, J . L. Acumulação de Capital, Taxa Real de Câmbio e Catching-up: Teoria e evidência para o caso brasileiro. $10^{\circ}$ Fórum de Economia. São Paulo, set. 2013. Disponível em:

http:/ / eesp.fgv.br/ sites/ eesp.fgv.br/ files/ file/ J ose\%20Luiz\%20Oreiro\%20foru m\%202013.pdf. Acesso em: 11 dez. 2016.

SOUZA, N. D. J . Abertura comercial e crescimento dos Estados Brasileiros, 1991/ 2000. Teoria e Evidência Econômica, Passo Fundo, RS., v. V.11, n.N. 21, p. 41-61, 2003.

TELES, V. K. Choques Cambiais, Política Monetária e Equilíbrio Externo da Economia Brasileira em um Ambiente de Hysteresis. Economia Aplicada (Impresso), USP, v. 9, n.3, p. 415-426, 2005.

TREGENNA, F. (2009). "Characterizing deindustrialization: an analysis of changes in manufacturing employment and output internationally". Cambridge J ournal of economics, Vol. 33.

VERÍSSIMO, M. P.; XAVIER, C. L.; VIEIRA, F. V. Taxa de Câmbio e Preços de Commodities: Uma Investigação sobre a Hipótese da Doença Holandesa no Brasil. In: XXXVIII Encontro Nacional de Economia, 2010, Salvador. XXXVIII Encontro Nacional de Economia, 2010.

\section{APÊNDICE}

Tabela 7. Teste LM para identificação de autocorrelação

\begin{tabular}{llll} 
Lag & Df & Chi $^{2}$ & Valor $\mathrm{p}$ \\
\hline 1 & 9 & 12.53 & 0.185 \\
2 & 9 & 13.06 & 0.16 \\
3 & 9 & 6.65 & 0.673 \\
4 & 9 & 5.67 & 0.772 \\
\hline
\end{tabular}

H0: no autocorrelation at lag order.

Ha: Autocorrelation at lag order. 


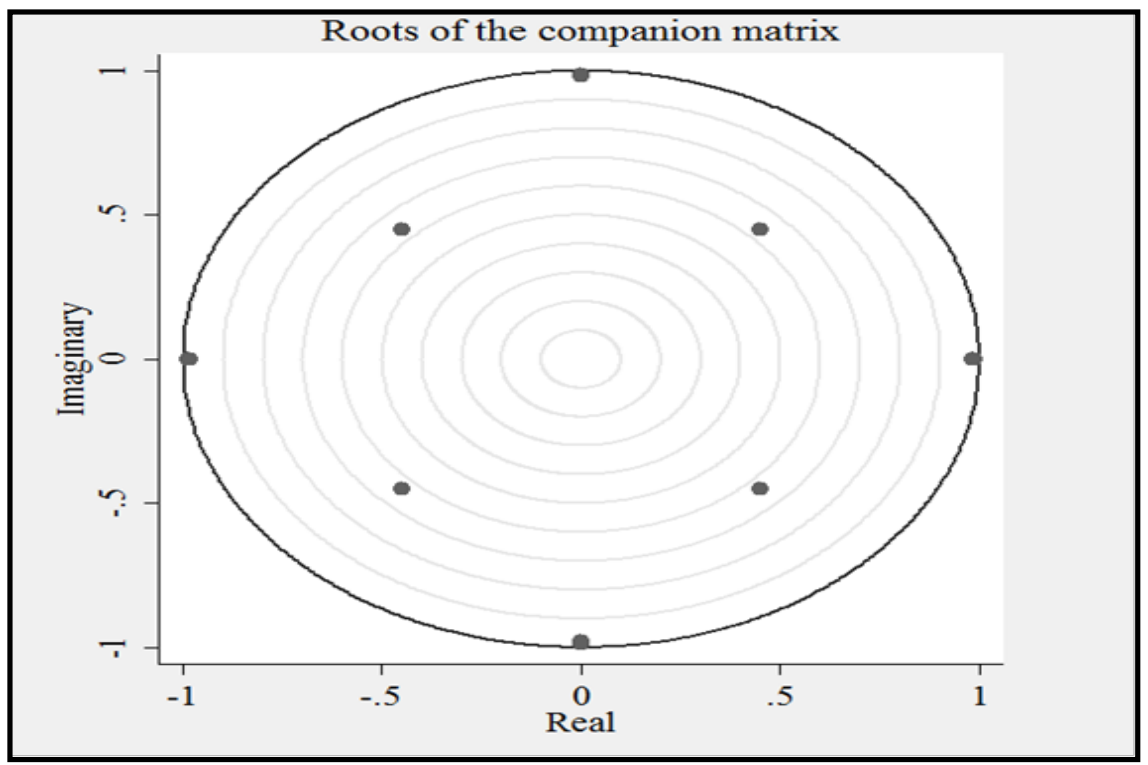

Figura A1. Condição de estabilidade dos autovalores.

Fonte: Elaborado pelos autores com base no software Stata 13. 